\title{
Effect of $\mathrm{CaCO}_{3}$ Particles Size and Content on Impact Strenght of Kenaf/ $\mathrm{CaCO}_{3} /$ Epoxy Resin Hybrid Composites
}

\author{
Harini Sosiati ${ }^{\star}$, Cahyo Trisedyo Utomo, Iwan Setiono and Cahyo Budiyantoro \\ Department of Mechanical Engineering, Faculty of Engineering, Universitas Muhammadiyah Yogyakarta \\ "hsosiati@ft.umy.ac.id
}

\begin{abstract}
Thermoplastic and thermoset polymer composites reinforced with kenaf fiber or $\mathrm{CaCO}_{3}$ have been extensively investigated. However, the study on the combination of kenaf fiber and $\mathrm{CaCO}_{3}$ reinforced epoxy resin is rare. This research discussed the effect of $\mathrm{CaCO}_{3}$ particle size and the ratio of kenaf to $\mathrm{CaCO}_{3}$ content on the impact strength of alkali-treated kenaf/ $\mathrm{CaCO}_{3} /$ epoxy resin hybrid composites. Thirty $\%$ of the hybrid kenaf fibers and $\mathrm{CaCO}_{3}$ particles reinforced epoxy resin composites were fabricated by hand lay-up technique followed by cold press. Impact test of the composite specimens was conducted using a Charpy Impact test according to ASTM D 6110. The morphology of impact fracture surface was examined by scanning electron microscopy (SEM). The results showed that the impact strength of the hybrid composite increased with the decrease of $\mathrm{CaCO}_{3}$ particle size, and increasing the ratio of kenaf to $\mathrm{CaCO}_{3}$. Interfacial bonding between the reinforcement (kenaf and $\mathrm{CaCO}_{3}$ ) and epoxy resin matrix, the uniform dispersion of kenaf and $\mathrm{CaCO}_{3}$ within the epoxy resin matrix are two crucial factors influencing the impact strength of the composite.
\end{abstract}

Keywords: Kenaf fiber; $\mathrm{CaCO}_{3}$; epoxy resin; hybrid composite; impact strength.

\section{INTRODUCTION}

The beneficial composite properties such as lightweight and corrosion resistant have attracted research interest and developing the material for automotive interior and exterior components manufacturer. Epoxy resin is one of the thermoset polymers used as a matrix material for the natural fiber composite that is suitable for exterior/outdoor, automotive component due to their resistant to ultraviolet (UV) ${ }^{[1]}$.

Epoxy resin reinforced with various natural fibers composites have been extensively studied in making industrial products due to their excellent mechanical and thermal properties. Kenaf is abundantly available in Indonesia and is one of the natural fiber types that have been first used as a raw material for the interior automotive components in Toyota Boshoku Corporation.

Alkali-treated kenaf reinforced epoxy resin composites with different fiber contents from $5 \%$ to $25 \%$ have been studied and indicates that the flexural strength increased with the fiber loading, $15 \%$ fiber loading showed the highest impact strength ${ }^{[2]}$. The asymmetrical fibers altered the ability to transfer stress from the matrix to the fibers ${ }^{[3]}$. Fauzi et al. ${ }^{[4]}$ have also researched the mechanical properties of kenaf reinforced epoxy resin composites affected by the fiber content. The mechanical properties (tensile, flexural, and impact strength), however, are much lower in comparison with the results reported by Abu Bakar et al. ${ }^{[2]}$. Introducing kenaf fiber at concentrations ranging from 5 to $20 \%$ into epoxy resin drastically decreased the mechanical properties ${ }^{[4]}$. The results of impact strength were 3 $\mathrm{kJ} / \mathrm{m}^{2}$ and $0.05 \mathrm{~kJ} / \mathrm{m}^{2}$ for neat epoxy resin and untreated-kenaf/epoxy resin, which were fabricated in a cold press glass molding at room temperature for $24 \mathrm{~h}$ with $5 \%$ fiber loading, respectively. However, Abu Bakar et al. ${ }^{[2]}$ showed impact strength of $5 \mathrm{~kJ} / \mathrm{m}^{2}$ and 
$\sim 3.2 \mathrm{~kJ} / \mathrm{m}^{2}$ for neat epoxy resin and untreated-kenaf/epoxy resin which were fabricated in a hot press stainless-steel molding at $100^{\circ} \mathrm{C}$ for $25-50 \mathrm{~min}$ with $5 \%$ fiber loading, respectively. The significant difference in the impact strength values might be affected by their differences in composite preparation. The uniformity of kenaf fiber dispersion within the epoxy resin matrix is a significant factor affecting the mechanical properties of the composite.

On the other hand, except for the natural fiber, $\mathrm{CaCO}_{3}$ as an abundant mineral, has been used as a filler of both the thermoplastic and thermoset polymers because it can improve the mechanical properties of the related composite ${ }^{[5,6]}$. Our previous work has shown changes in the mechanical properties (tensile and impact strength, and hardness) of $\mathrm{CaCO}_{3} /$ polypropylene (PP) composites by the addition of $\mathrm{CaCO}_{3}$ from $5 \%$ to $25 \%{ }^{5}$. $\mathrm{CaCO}_{3}$ content of $15 \%$ reached the highest tensile strength $(24.9 \mathrm{MPa})$ and hardness $(69$ D-shore), and 5\% was the lowest. The highest impact strength was achieved at $5 \% \mathrm{CaCO}_{3}$ content. All the properties decreased at $25 \% \mathrm{CaCO}_{3}$ content. Seemingly, the composite brittleness increases with the addition of $\mathrm{CaCO}_{3}$ at higher concentrations. In this case, the dispersion of $\mathrm{CaCO}_{3}$ within the PP matrix played a crucial role in the alteration of the mechanical properties. Furthermore, the impact strength of $\mathrm{CaCO}_{3}$ reinforced epoxy resin composite with various $\mathrm{CaCO}_{3}$ concentrations from 10 to $60 \%$ studied by Nwoye et al. ${ }^{[6]}$ has indicated that lower $\mathrm{CaCO}_{3}$ content yields higher impact strength of $\mathrm{CaCO}_{3} /$ epoxy resin composite.

Some methods that can improve the polymer composite properties are as follows: by varying fabrication of the hybrid composite; various fiber types reinforced single matrix type, single fiber type or single particulate type reinforced some matrix types and variation of fiber and particulate filled in a single matrix type. Some investigation results have reported that the significantly improve tensile properties have been shown in the composite of kenaf/PP with impregnation of $\mathrm{CaCO}_{3}$ nanoparticles ${ }^{[7]}$. The highest tensile strength $(\sim 51.61 \mathrm{MPa})$ has been attained at $2.57 \% \mathrm{CaCO}_{3}$ loading, suggesting that the addition of nanoscale particles is an effective way of enhancing the composite properties. No data of impact strength for this composite has been reported. Besides, the impact energy of the Luffa cylindrica/polyester composites with different micro fillers $\left(\mathrm{CaCO}_{3}\right.$, $\mathrm{Al}_{2} \mathrm{O}_{3}$ dan $\mathrm{TiO}_{2}$ ) has shown that the composition of polyester plus Luffa fiber $(10 \%)+$ $\mathrm{CaCO}_{3}(5 \%)$ has achieved the highest impact energy (8 Joule). Still no information for a fixed size of micro fillers was found ${ }^{[8]}$. In addition, the study on the hybrid composite of kenaf/ $\mathrm{CaCO}_{3} /$ epoxy is scarce.

Alkali-treated fiber is recommended for enhancing the interfacial bonding between the fiber surface and the matrix ${ }^{[2,9]}$. In this work, the impact strength of the alkali-treated kenaf $/ \mathrm{CaCO}_{3}$ /epoxy resin hybrid composites affected by the different $\mathrm{CaCO}_{3}$ particle size, and the different ratio of kenaf to $\mathrm{CaCO}_{3}$ or $\mathrm{CaCO}_{3}$ content were investigated. The discussion focused on the impact fracture surface and the degree of dispersion of the reinforcing material in the matrix, related to the alteration of the impact strength. As previously mentioned, this composite type is acceptable for outdoor application such as car bumper and mirror cover. Thus, the information on impact strength is noteworthy. 


\section{METHOD}

\section{Materials}

Kenaf fibers and Pro analysis $\mathrm{CaCO}_{3}$ powder used as reinforcing materials were purchased from Balittas, Malang, Indonesia, and C.V. Chem-Mix Pratama, Yogyakarta, Indonesia, respectively. The epoxy resin matrix which consisted of resin (Bisphenol Aepiclorohydrin) and hardener (Polyaminoamide) from EposchÖn trademark was used with a ratio of $1: 1$ as a matrix material.

\section{Preparation of Reinforcement Materials}

Alkalization of $6 \mathrm{~mm}$ length kenaf fibers used in this work was described elsewhere ${ }^{[10]}$. $\mathrm{CaCO}_{3}$ powder was sieved into 200 mesh $(74 \mu \mathrm{m})$, and 400 mesh $(37 \mu \mathrm{m})$. The $\mathrm{CaCO}_{3}$ powder used as micro fillers had three different particle sizes: i.e., as-received $\mathrm{CaCO}_{3}, 74$, and $37 \mu \mathrm{m}$. The smallest size $\mathrm{CaCO}_{3}$ was subsequently used for various ratios of kenaf to $\mathrm{CaCO}_{3}$ ratio in (w/w): i.e., 20:10, 15:15 and 10:20. In this case, either alkali-treated kenaf fiber or $\mathrm{CaCO}_{3}$ powder tended to be agglomerated. Therefore, before fabricating the composites, kenaf fibers and $\mathrm{CaCO}_{3}$ powder were dried in an oven at $105^{\circ} \mathrm{C}$ for about 30 min to vaporize the water molecules contained in those materials. Drying was repeated until water molecules wholly evaporated.

\section{Composite Fabrication}

The kenaf $/ \mathrm{CaCO}_{3} /$ epoxy resin hybrid composites with $30 \%$ reinforcement volume fraction were manufactured by hand lay-up technique followed by cold press. There were two types of composites. One is fabricated with varying $\mathrm{CaCO}_{3}$ particle size and using kenaf $/ \mathrm{CaCO}_{3}$ ratio of $20 / 10$, and the other is those with varying kenaf/CaCO 3 ratio. The untreated kenaf/epoxy resin and treated kenaf/epoxy resin composites without $\mathrm{CaCO}_{3}$ micro filler were prepared for comparison. Before pressing the composites, each variation $\mathrm{CaCO}_{3}$ particle and epoxy resin were firstly mixed manually. After that, chopped kenaf fibers $6 \mathrm{~mm}$ in length were inserted into the mixed components gradually and continuously blended. The variety of $\mathrm{CaCO}_{3}$ particle size and the ratio of kenaf to $\mathrm{CaCO}_{3}$ are described above.

\section{Impact Testing}

The composite sheet specimens (Fig.1a) were prepared for the Charpy impact test specimen according to ASTM D 6110 with the specimen dimension of 127 x 12.7 x $3 \mathrm{~mm}$ and the depth of the notch was $10.16 \pm 0.05 \mathrm{~mm}$ with angle $45 \pm 1^{\circ}$. In this research, five specimens were prepared for each parameter variation. The impact testing was conducted with applied force set at a constant height and weight pendulum of $0.33 \mathrm{~m}$ and $1.8 \mathrm{~kg}$, respectively. The composite specimens after impact testing are shown in Fig. 1b.

\section{Microstructural Characterization}

The impact fracture surfaces (Fig. 1b, see arrows) were examined by scanning electron microscopy (SEM) to understand the correlation between impact strength affected by different $\mathrm{CaCO}_{3}$ particle size and the ratio of kenaf to $\mathrm{CaCO}_{3}$ content and the morphologies of fracture surfaces. The distribution of kenaf fibers in the epoxy resin matrix was observed from a cross-section view (Fig. 1c) using a digital optical microscope. 

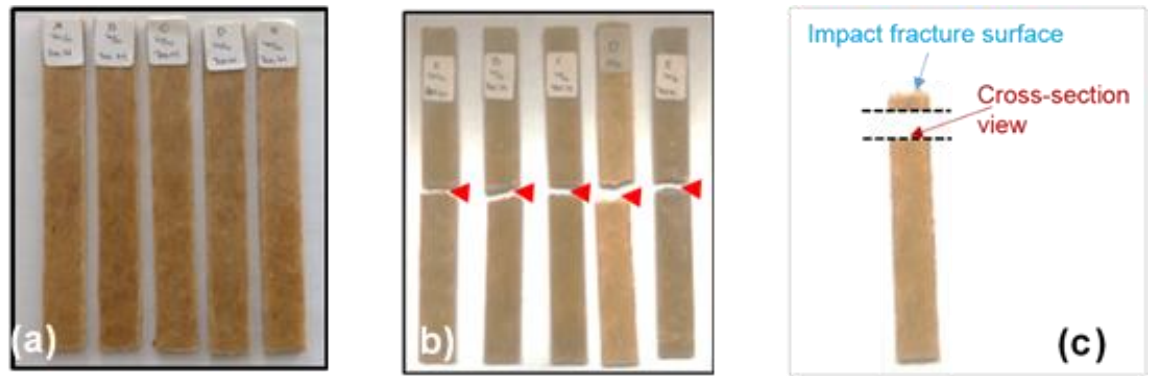

Figure 1. Kenaf/ $\mathrm{CaCO}_{3} /$ epoxy resin composite specimens. (a) and (b) are before and after impact testing, respectively, and (c) is showing a cross-section area for observation with a digital optical microscope.

\section{RESULTS AND DISCUSSION}

\section{Impact Strength of $\mathrm{Kenaf} / \mathrm{CaCO}_{3} / \mathrm{Epoxy}$ resin}

Figure 2 demonstrates the impact strength of the kenaf/CaCO $3 /$ epoxy resin composites that were evaluated from the absorbed energy resulted from impact testing. Alkali-treated kenaf/epoxy composite with a 30\% volume fraction of reinforcement shows higher impact strength than that with untreated kenaf, indicating better interfacial bonding between fiber surface and epoxy matrix due to alkalization ${ }^{[9,10]}$. Impact strengths for both untreated and treated kenaf/epoxy composites are higher compared to those reported by Abu Bakar et al. ${ }^{[2]}$ with $25 \%$ fiber loading and Fauzi et al. ${ }^{[4]}$ that used fiber content from $5 \%$ to $20 \%$.

The addition of $\mathrm{CaCO}_{3}$ into treated-kenaf/epoxy resin composite did not show the expected results, leading to a decrease in the impact strength of the hybrid composites decreased significantly. A low degree of dispersion of the reinforcing materials in the matrix due to the hygroscopic property of $\mathrm{CaCO}_{3}$ might be the cause. However, impact strength showed a trend to increase as smaller $\mathrm{CaCO}_{3}$ particle size gradually. The smaller $\mathrm{CaCO}_{3}$ particles may have a higher degree of dispersion in the matrix and made stronger interfacial bonding with the epoxy matrix compared to the bigger ones ${ }^{[11]}$. The enhancement of impact strength depends not only on the size of the fillers but also on its shape, aggregate size, surface feature, content, and uniformity of dispersion within the matrix ${ }^{[11-13]}$.

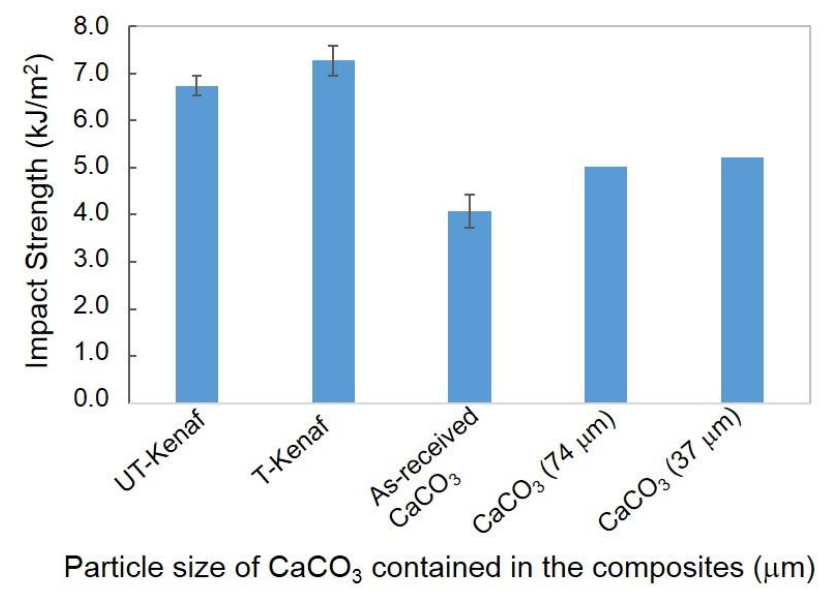

Figure 2. Effect of $\mathrm{CaCO}_{3}$ particle size on the impact strength of kenaf/ $\mathrm{CaCO}_{3} /$ epoxy. UT-kenaf and $\mathrm{T}$ kenaf are the composites without $\mathrm{CaCO}_{3}$. UT: untreated- and $\mathrm{T}$ : treated or alkali-treated-kenaf fibers. 
The influence of the ratio of kenaf to $\mathrm{CaCO}_{3}$ on impact strength that was studied using the smallest size of $\mathrm{CaCO}_{3}$ (400 mesh or $37 \mathrm{~mm}$ ) shows that it decreased with decreasing kenaf content (Fig.2). This result explains that the addition of a higher amount of $\mathrm{CaCO}_{3}$ than kenaf fiber leads to a reduction in impact strength, and the composite tends to be brittle. This trend is consistent with the result reported by Nwoye et al. (7), who had studied the $\mathrm{CaCO}_{3}$ /epoxy composite. Besides, nano- $\mathrm{CaCO}_{3}$ reinforced epoxy composites revealed a significant improvement in impact strength at $4 \%$ nano- $\mathrm{CaCO}_{3}$ content, but it drastically decreased by $10 \%$ (14). Changes in impact strength affected by $\mathrm{CaCO}_{3}$ particle size, and also the ratio of kenaf to $\mathrm{CaCO}_{3}$ will be discussed from the following morphologies of the impact fracture surface.

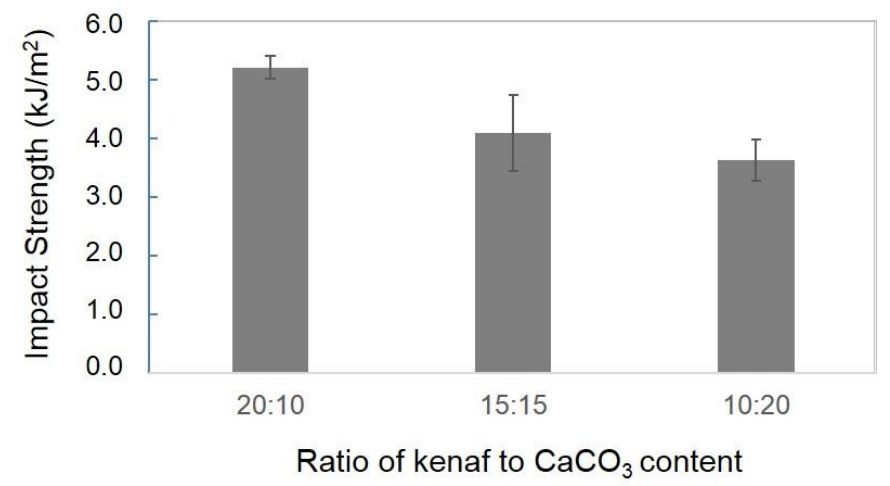

Figure 3. The effect of a ratio of kenaf to $\mathrm{CaCO}_{3}$ on the impact strength of kenaf/CaCO $3 /$ epoxy.

\section{Impact Fracture Surface}

SEM images of the fracture surface of the impact tested composite specimens either due to different $\mathrm{CaCO}_{3}$ particle size or the ratio of kenaf to $\mathrm{CaCO}_{3}$ content showed the brittle surface with microvoids formed in entire regions. The manual blending of reinforcement materials and epoxy resin matrix during the composite fabrication might be led the air bubbles trapped into the composites and formed the voids. The presence of a high density of voids made the material tough in absorbing a lot of energy and led to reducing the impact strength of the composites.
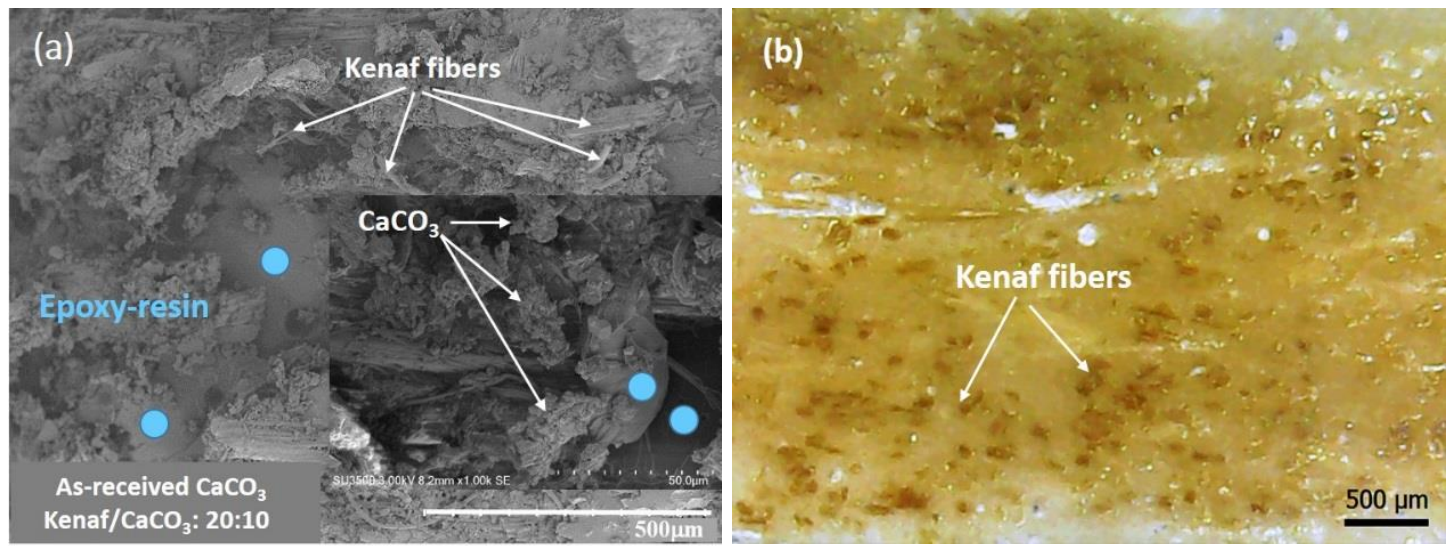

Figure 4. (a) SEM image of impact fracture surface specimen with as-received $\mathrm{CaCO}_{3}$ particles and (b) Optical micrograph of the related specimen showing inhomogeneous fiber distribution. 
The lowest impact strength of the composite with as-received $\mathrm{CaCO}_{3}$ particles can be understood from Fig. $4 \mathrm{a}$ and $4 \mathrm{~b}$. The observed agglomerated $\mathrm{CaCO}_{3}$ particles with the size between 200-300 $\mathrm{mm}$ and some regions of pure epoxy resin indicating that $\mathrm{CaCO}_{3}$ particles were not well blended in the epoxy matrix (Fig.4a, see blue circles). Kenaf fibers were partly fibrillated as exhibited in different sizes. To confirm the characterization of the distribution of the reinforcement materials within the matrix by SEM, the observation of those in the entire region specimen from the cross-section view (Fig. 1c) is necessary. Thus, it has to be observed at a low magnification image, which can be conducted with an optical microscope. The optical micrograph of the cross-sectional specimen (Fig.4b) had confirmed the relatively inhomogeneous distribution of the fibers in the matrix. The distribution of $\mathrm{CaCO}_{3}$ particles in, however, was unclear.

The composite specimen with $\mathrm{CaCO}_{3}$ particles 200 mesh $(74 \mu \mathrm{m})$ depicts slightly different morphology from that with as-received $\mathrm{CaCO}_{3}$. The fibrillated kenaf fibers were also observed (Fig.5a, see fat arrows), and the distribution of the fibers in the matrix revealed in Fig. $5 b$ is relatively similar to that in the specimen shown in Fig. 4 b. Besides, $\mathrm{CaCO}_{3}$ particles were not agglomerated and well embedded in the matrix with a relatively high degree of dispersion, resulting in a strong networking structure between $\mathrm{CaCO}_{3}$ and epoxy matrix. It also showed good interfacial bonding between kenaf fibers and matrix filled $\mathrm{CaCO}_{3}$, suggesting better impact strength compared to the specimen reinforced with asreceived $\mathrm{CaCO}_{3}$ (Fig. 4a).
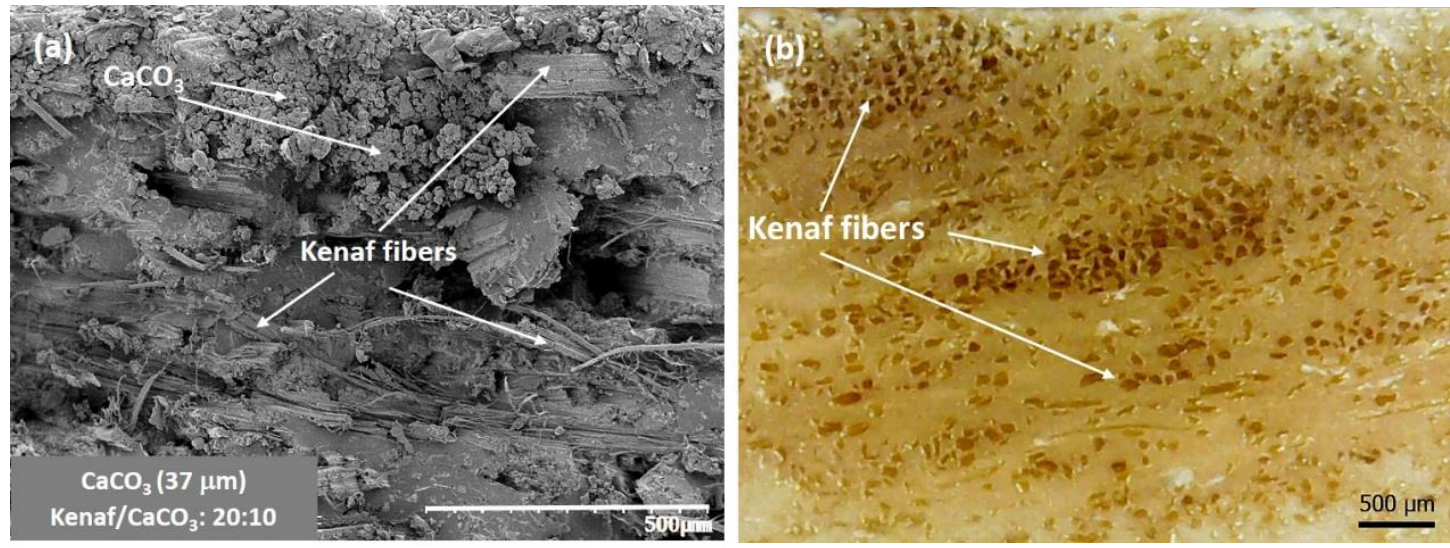

Figure 5. (a) SEM image of impact fracture surface specimen with $\mathrm{CaCO}_{3}$ particles 400 mesh and (b) Optical micrograph of the related specimen showing relatively homogeneous fiber distribution

On the other hand, a decrease of impact strength due to increasing $\mathrm{CaCO}_{3}$ content or reducing the amount of kenaf (Fig.3) was correlated to the morphologies of impact fracture surface in Fig.5a, 6a, and 6b. In these relationships, Fig.5a shows the morphology of composite specimen with the lowest $\mathrm{CaCO}_{3}$ content or the highest ratio of kenaf to $\mathrm{CaCO}_{3}$ content. The smaller, the amount of kenaf fiber shown in the SEM images (Fig.5a, $6 \mathrm{a}$, and $6 \mathrm{~b}$ ) seems to be consistent with the proportion of a ratio of kenaf to $\mathrm{CaCO}_{3}$ content. Some agglomerated $\mathrm{CaCO}_{3}$ particles were detected in the specimen with a ratio of 15:15 (Fig.6a). In contrast, those were not shown in a ratio of 10:20 (Fig.6b) suggesting the $\mathrm{CaCO}_{3}$ particles had well dispersed in the epoxy matrix. The characteristic of the entire surface morphology in a specimen with the highest $\mathrm{CaCO}_{3}$ content showed the brittle fracture surface. There were some broken kenaf fibers formed in this specimen (Fig.6b, see yellow arrows). It can be understood, therefore, that the presence of kenaf fibers play a 
crucial role in enhancing interfacial adhesion between the matrix and the reinforcement materials.
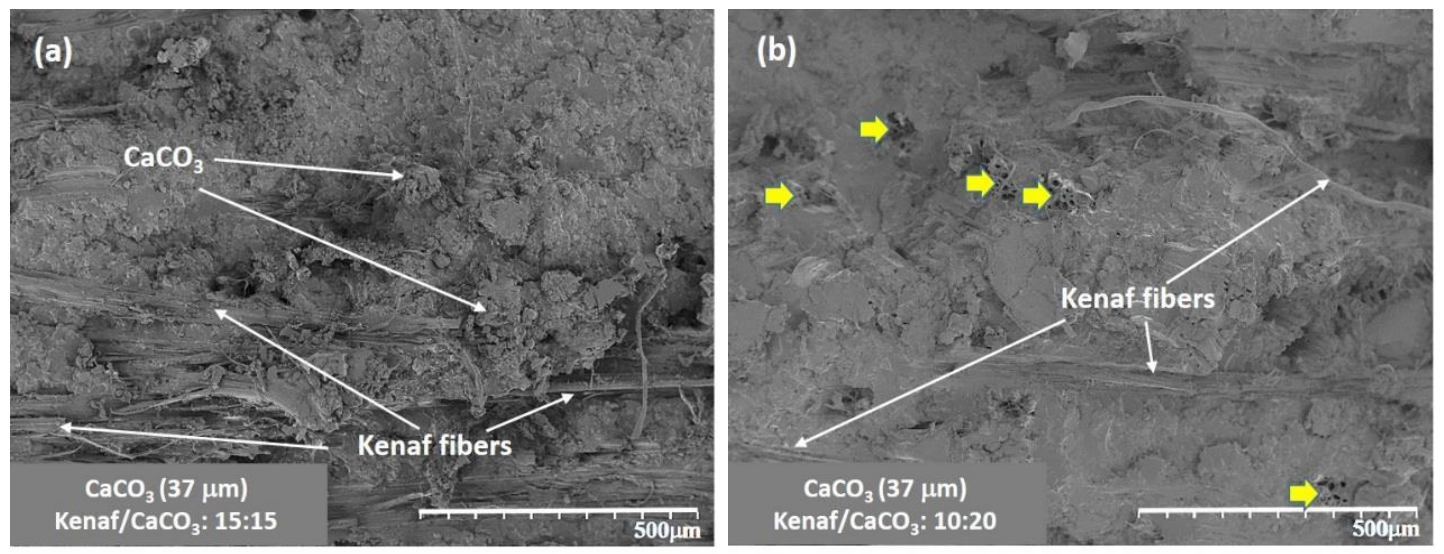

Figure 6. SEM images of impact fracture surface specimen with kenaf/ $\mathrm{CaCO}_{3}$ ratio 15:15 (a) and 10:20 (b).

\section{CONCLUSIONS}

SEM results of kenaf/CaCO $3 /$ epoxy resin hybrid composite have verified some critical points. the addition of caco $\mathrm{CaCO}_{3}$ particles in the kenaf/epoxy resin composite does not improve the impact strength of the composite due to a hygroscopic property of $\mathrm{CaCO}_{3}$, especially the untreated $\mathrm{CaCO}_{3}$ (as-received $\mathrm{CaCO}_{3}$ ). $\mathrm{CaCO}_{3}$ tends to agglomerate and inhibits the interaction between kenaf fiber and epoxy matrix, as smaller the $\mathrm{CaCO}_{3}$ particles improve the impact strength of the hybrid composite, while as higher the $\mathrm{CaCO}_{3}$ content decreases the impact strength. Degree of dispersion of fillers in the matrix and, excellent adhesion between the reinforcements and the matrix acts as essential roles in affecting the impact strength of the composites. The important finding resulted from this research is the impact strength of the composite can be improved by adding a higher amount of kenaf fibers than that of $\mathrm{CaCO}_{3}$. These results would be useful for the application and fundamental science of the composites.

\section{ACKNOWLEDGEMENTS}

This research was supported by a research grant of "Unggulan Prodi 2018", Universitas Muhammadiyah Yogyakarta with the contract no: 1143/SP2-PL/LP3M-UMY/III/2018. Our grateful thank goes to Dr. Sinin bin Hamdan, Universiti Malaysia Sarawak, Malaysia for his comments on the draft manuscript.

\section{REFERENCES}

1 González, M. G., Cabanelas, J. C., \& Baselga, J. 2012. Applications of FTIR on Epoxy Resins - Identification, Monitoring the Curing Process, Phase Separation and Water Uptake. Infrared Spectrosc. - Mater. Sci. Eng. Technol., Vol. 2, 261.

2 Abu Bakar, M. A., Ahmad, S., \& Kuntjoro, W. 2010. The mechanical properties of treated and untreated kenaf fibre reinforced epoxy composite. J. Biobased Mater. Bioenergy, Vol. 4, No. 2, 159.

3 Singh, J. S. K., Ching, Y. C., Liu, D. S., Ching, K. Y., Razali, S., \& Gan, S. N. 2018. Effects of PTFE micro-particles on the fiber-matrix interface of polyoxymethylene/glass fiber/polytetrafluoroethylene composites. Materials (Basel)., Vol. 11, No. 11, 1. 
4 Fauzi, F. A., Ghazalli, Z., \& Siregar, J. P. 2016. Effect of various kenaf fiber content on the mechanical properties of composites. J. Mech. Eng. Sci., Vol. 10, No. 3, 2226.

5 Budiyantoro, C., Sosiati, H., Kamiel, B. P., \& Fikri, M. L. S. 2018. The effect of $\mathrm{CaCO}_{3}$ filler component on mechanical properties of polypropylene. IOP Conf. Ser. Mater. Sci. Eng., Vol. 432, 1.

6 Nwoye, C. I., Obelle, M. C., Nawkpa, S. O., Oniya, C. W., Obuekwe, I., \& Idenyi, N. E. 2015. Predictability of the Impact Strength of $\mathrm{CaCO}_{3}$-Epoxy Resin Composite Based on $\mathrm{CaCO}_{3}$ Input Concentration and Sustained Stress at Impact, International Journal of Materials Lifetime, Vol. 2, No. 1, 6.

7 Shi, J., Shi, S. Q., Barnes, H. M., Horstemeyer, M. F., \& Wang, G. 2011. Kenaf bast fibers - Part II: Inorganic nanoparticle impregnation for polymer composites. Int. J. Polym. Sci., Vol. 2011, 1.

8 Patel, V. K., \& Dhanola, A. 2016. Influence of $\mathrm{CaCO}_{3}, \mathrm{Al}_{2} \mathrm{O}_{3}$, and $\mathrm{TiO}_{2}$ microfillers on physico-mechanical properties of Luffa cylindrica/polyester composites. Eng. Sci. Technol. an Int. J., Vol. 19, 676.

9 Sosiati, H., Nahyudin, A., Wijayanti, D. A., Triyana, K., \& Sudarisman. 2018. Effect of alkali treatment and MAPP addition on tensile strength of sisal/polypropylene composites. J. Adv. Manuf. Technol., Vol. 12, No. 2, 65.

10 Sosiati, H., Shofie, Y. A., \& Nugroho, A. W. 2018. Tensile properties of Kenaf/Eglass reinforced hybrid polypropylene (PP) composites with different fiber loading. Evergreen,Vol. 5, No. 2, 1.

11 Yang, G., Heo, Y. J., \& Park, S. J. 2019. Effect of morphology of calcium carbonate on toughness behavior and thermal stability of epoxy-based composites. Processes Vol. 7, 178.

12 Li, L., Zou, H., Shao, L., Wang, G., \& Chen, J. 2005. Study on mechanical property of epoxy composite filled with nano-sized calcium carbonate particles. J. Mater. Sci., Vol. 40, 1297.

13 Mohan, T. P., \& Kanny, K. 2018. Thermal, mechanical and physical properties of nanoegg shell particle-filled epoxy nanocomposites. J. Compos. Mater., Vol. 52, 3989. 